\title{
El maltrato parece ser un factor de riesgo independiente de mortalidad en los pacientes ancianos
}

The mortality of elder mistreatment. Lachs M., Williams C., O'Brien S. JAMA.1998;280:428-432

\begin{abstract}
Objetivo
Estimar la contribución independiente de la negligencia y el abuso, a las causas de mortalidad en una cohorte de ancianos residentes en la comunidad.

\section{Diseño}

Estudio prospectivo de cohortes con al menos 9 años de seguimiento.

Lugar

Población establecida para estudios epidemiológicos (New Heaven EPESE Study, National Institute on Aging, EE.UU.)

\section{Pacientes}

Adultos mayores de 65 años en 1982 residentes en la comunidad pertenecientes a la población en estudio. Se siguieron tres subgrupos: 1. el de aquellos en los que se verificó maltrato sostenido por parte de otra persona; 2 . el de aquellos en los que se corroboró auto-negligencia y 3. el de otros miembros de la cohorte que no tuvieron contacto con el servicio de protección de ancianos (Esto implica que no eran maltratados o que el maltrato no fue detectado por personas cercanas al individuo y no fue denunciado).

Se definió abuso de ancianos como la provocación de dolor físico, lesión o angustia mental o la privación por parte del cuidador de los servicios necesarios para mantener la salud física y mental. Se definió como negligente a aquella persona sola que no fuera capaz de proveerse los servicios necesarios para mantener su salud física y mental (autonegligente) o que no estuviera recibiendo esos servicios de parte de su cuidador responsable.
\end{abstract}

\section{Evaluación de factores pronósticos}

Se evaluaron múltiples variables entre las que se incluyeron las demográficas (edad, sexo, raza, educación e ingresos), las relacionadas con la salud (presencia de enfermedades crónicas, índice de masa corporal, etc.), las relacionadas con la funcionalidad (actividades de la vida diaria), las redes y el soporte social, los elementos psicosociales (Escala de Depresión del centro de estudios epidemiológicos) y la performance cognitiva.

\section{Medición del resultado principal}

Se evaluó el riesgo de muerte ajustado en pacientes maltratados y autonegligentes.

\section{Resultados principales}

Al comienzo del seguimiento (primeros 5 años), las tasas de sobrevida fueron similares en los 3 grupos, pero hacia el final, los miembros del grupo seguido por maltrato tuvieron menor sobrevida ( $9 \%$ ) que aquellos seguidos por autonegligencia (17\%) o aquellos sin contacto con el sistema de protección (40\%) ( $\mathrm{P}<0.001$ para las diferencias). El riesgo de morir ajustado sólo por el período de seguimiento fue sustancialmente mayor en los individuos maltratados (RR* 5.1; IC95\%, 2.89.5) y en los autonegligentes (RR* 3.1; IC95\%,2.3-4.2). El análisis posterior, ajustando los resultados por características demográficas, funcionalidad, redes sociales, estado cognitivo y sintomatología de depresión, disminuyó la magnitud de la asociación entre el maltrato y todas las causas de mortalidad. Las caracteristicas demográficas y la funcionalidad fueron las variables que más influyeron sobre los Odds Ratios* ${ }^{*}$. De todos modos, luego de ajustar por todas estas variables, el riesgo de muerte se mantuvo elevado en el grupo de los que recibían maltrato ( RR* $\left.{ }^{*} 3.1 ; \mathrm{IC} 95 \%, 1.4-6.7\right)$ y en el de los autonegligentes (RR,1.7; IC95\% 1.2-2.5) cuando se los comparó con los otros miembros de la cohorte. Las causas más comunes de muerte para los 3 grupos se distribuyeron en forma similar. Ninguna muerte en los grupos de maltrato y autonegligencia fue debida a lesiones.

Fuente de financiamiento: National Institute on Aging.

\section{COMENTARIO}

Las estadísticas señalan que las principales causas de muerte entre los adultos mayores de 65 años son las enfermedades cardíacas, las neoplasias, la patología cerebrovascular, la EPOC y enfermedades relacionadas, la neumonía y la gripe. Este trabajo Llama nuestra atención y advierte sobre un problema frecuentemente olvidado: el maltrato, no sólo como una cuestión ética sino como un elemento con probable peso independiente sobre la mortalidad en los ancianos. Se ha calculado que la prevalencia de maltrato en este grupo etário es del $3.2 \%$ pero se estima que esta cifra subestimaría el problema ${ }^{1}$. Este trabajo halló que la mortalidad en el grupo maltratado y autonegligente fue mayor y que esta diferencia persistió luego de ajustar los resultados en función de variables universalmente reconocidas como asociadas con el incremento en la mortalidad. Resulta llamativo que las muertes en los grupos en estudio no se debieron, precisamente, a lesiones. Esto nos hace pensar que el maltrato contribuiría a la mortalidad de un modo diferente, no aclarado (poca accesibilidad al cuidado médico, baja adherencia a los tratamientos, etc.) o que no se han identificado otras variables que podrían estar actuando como confundidoras. Por ejemplo, Los pacientes maltratados pertenecían a un grupo que estaba en contacto con un servicio gubernamental de protección (al que accedieron *Ver Glosario

\section{Dra. Paula Carrete}

Unidad de Medicina Familiar y Preventiva. Hospital Italiano de Buenos Aires.

Referencias

1. Rosenblat DE, Cho KH, Durance PW. Reporting mistreatment of older adults: The role of physicians. JAGS 1996; 44: 65-70.

2. Daichman LS, Wolf R, Bennet G, Penhale B, Podnieks E. Action in elder abuse: An overview. World Congrss of Gerontology, Adelaide, Australia, 1997. cuando el maltrato fue denunciado) y desconocemos si esto seleccionó una población particular de ancianos en riesgo. Si es así, no sería posible generalizar los resultados. Más allá de esto, es importante recordar que el diagnóstico de maltrato no es simple y requiere de un alto índice de sospecha. Ciertas condiciones deberían despertar la alarma: el retardo entre la ocurrencia de una lesión física y la consulta, la disparidad entre los relatos del paciente y su cuidador, las consultas frecuentes a Las salas de guardia por exacerbación de patologías crónicas a pesar de haber detallado el tratamiento en varias oportunidades y la reacción de defensa ante el mínimo intento de acercamiento ${ }^{2}$. Otros datos sugerentes de maltrato son la higiene pobre, la sedación desproporcionada, la vestimenta inapropiada, la sobre o submedicación ${ }^{2}$. Socialmente existe poca conciencia sobre el problema, tanto el abusador como su víctima suelen negarlo y el médico frecuentemente encuentra numerosas dificultades para probar y denunciar su existencia. De todos modos la inquietud está planteada, y si bien es necesario el desarrollo de nuevos trabajos para confirmar (o no) los resultados presentados, esto no nos exime a los trabajadores de la salud de pensar en este problema, de rastrearlo en la población con la que trabajamos y de instrumentar las medidas necesarias para intentar resolverlo. 